\title{
Beyond language and the subject: machinic enslavement in contemporary European cinema
}

\author{
Abstract \\ Contemporary subjection, notes Maurizio Lazzarato, has two very different dimensions, \\ subjectivation (our production as subjects) and machinic enslavement (the way in which \\ sub- and supra-individual human elements are put to work as cogs in complex machineries \\ that are never simply technical machines). Although the latter form of subjection is \\ increasingly dominant, critical theory almost always focuses on the former. With its \\ intrinsically machinic functioning, cinema seems ideally placed to open up our machinic \\ subjection to scrutiny. Can it become the Vertovian self-consciousness of a collective, \\ machinic subject, or is it simply condemned to anticipate and embody the way in which \\ consumer capitalism puts the human psyche and affectivity to work? Suggesting that such a \\ polarised set of alternatives is too schematic, this article probes four contemporary, and \\ very dissimilar, European films, sounding out their capacity to bring the machinic into view \\ and make it available for self-reflexive engagement. The article draws its main theoretical \\ inspiration from the work of contemporary social theorist, Maurizio Lazzarato, but also \\ draws on other thinkers where relevant. The films discussed are Ma part du gâteau \\ (Klapisch, 2011), Abenland (Geyrhalter, 2011), Lucy (Besson, 2014) and Vers Madrid: the \\ Burning Bright (George, 2012).
}

\section{Keywords:}

Machinic enslavement; crisis; Maurizio Lazzarato; Deleuze and Guattari; contemporary European cinema.

\section{Introduction}

Contemporary subjection, notes Maurizio Lazzarato, has two very different but complementary aspects. The more familiar relates to subjectivation and the different processes that constitute us as centred subjects with specific roles, responsibilities and rewards. The less often discussed but increasingly powerful aspect relates to our machinic enslavement, the way in which sub- and supra-individual physical, affective and intellectual human elements are inserted as cogs into larger assemblages or machineries that may include but are never limited to technical machines. The machinic, Lazzarato drily notes, is everywhere except in critical theory $(2014,13)$. To which one might add: the machinic is everywhere in cinema but nowhere to be seen. It is this invisible presence and its consequences for cinema's capacity to engage with the machinic dimension of contemporary subjection that this article will probe. It will begin by looking at the opening of a generally unremarkable middle-brow French film, Ma part du gâteau / My Piece of the Pie (2011), by Cédric Klapisch, suggesting that it is only when cinema's narrative drive is arrested that its machinic capacity can come to the fore and bring other unseen machineries into view. It will turn to the work of Lazzarato to develop the concepts of the machinic and of plural semiosis both in general and with respect to cinema, drawing on Jonathan Beller (2006) to supplement discussion of the latter. It will then apply the concepts discussed to 
three contemporary films, Nikolaus Geyrhalter's austere documentary, Abendland (2011), Luc Bessson's blockbuster, Lucy (2014), and Sylvain George's experimental documentary about the Spanish indignados movement, Vers Madrid: the Burning Bright (2012). Although the films might seem a rather eclectic choice, they have been deliberately selected to probe the range, potential and limits of cinema's engagement with the machinic at a time when our machinic enslavement is an increasingly dominant but still under-analysed aspect of our subjection. ${ }^{1}$ The liberatory potential of the machinic will also be developed as the article progresses.

In her Undoing the Demos (2015), political theorist Wendy Brown discusses how neoliberalism reframes all the basic elements of democracy in economic terms, leaving democracy itself as a hollow shell. She describes how the state is subordinated to the economy, subjects and institutions redefined as firms, the polis evacuated as a space of meaningful debate and self-sovereign homo politicus subordinated to homo oeconomicus. Despite the careful precision of her analysis, she pays little attention to the rising power of the machinic and its hold upon us, except in her all too brief evocation of the 'market metrics contouring every dimension of human conduct and institutions,' a comment that cries out for development $(2015,176)$. Engagement with the machinic is surely a vital part of any attempt to rethink democratic renewal. With its own machinic powers, has cinema the capacity to become the self-consciousness of such an engagement? This question also underlies what follows.

\section{Cinema's machinic powers}

Klapisch's Ma part du gâteau recounts the improbable encounter between a working-class woman and the financial trader whose decisions caused the closure of the factory where she worked. It begins with her suicide attempt at a child's birthday party, continues with her working as a cleaner for the trader, and ends when she forces him to come to Dunkirk to face the human consequences of his actions. The film undoubtedly casts light on evolutions in on-screen representation of workers and the difficulty of bringing the consequences of the systemic workings of financial capital within the frame of conventional narratives focussed on spatially circumscribed interpersonal dramas. By opposing a good ordinary woman and a heartless financier, it also joins a growing corpus of Crisis films which struggle to move beyond ultimately sterile moralising to a more politically productive framing. ${ }^{2}$ Where it is at its most interesting, dare one say, is in its title sequence, when, for a brief period, narrative is interrupted.

The sequence begins conventionally enough with a series of shots from the point of view of someone carrying a birthday cake, amidst a hubbub of voices and with various faces coming into view. Quickly abandoning this human perspective, it shifts to an overhead, fast motion shot of the cake being divided into slices as it moves from its insertion in family festivity towards the abstraction of geometry and division. This decentring of the human group is confirmed by the montage sequence that follows. Taking its rhythm from an edgy, up tempo piece of music entitled 'It's up to you' by Kraked Unit, it consists of the following: repeated shots of computer screens displaying lists of changing share prices and brightly coloured financial graphs or currency indices; lateral tracking shots from train windows of graffiti on concrete walls; views of a container port from a car window and a view of what we assume is the same car in the port; bird's-eye shots of containers from increasing heights (figure 1); lateral tracking shots of posters for concerts or political groups; brightly coloured overhead shots of a carnival parade; low-angle lateral tracking shots of high buildings; close- 
ups of hands clicking keyboard or calculator keys; a fast-motion long shot of activity in a trading room; lateral tracking shots of women crossing a bridge in what looks like Paris; shots from increasing distance of a woman smoking alone on a balcony with the City of London behind her; fast-motion shots brought together through jump cuts of people on an array of escalators; a shot of hands holding a handrail, maybe on the metro; a shot of people dismounting a metro car; a shot of mainly besuited people going through a group of metal doors; a shot of people at a bus stop as buses pass through the frame. Finally, as the sequence unwinds, there is an over-the-shoulder shot of two girls looking out to sea leading to another overhead shot of the cake being cut into portions. Then, we see a series of short medium close-ups of excited faces and hear voices linked to them as excitement turns to alarm: someone has swallowed pills and the emergency services must be called. We are back in a story.

Insert figure 1 here: Towards material abstraction, Ma part du gâteau, 2011.

Insert figure 2 here: Bodily cogs, Ma part du gâteau, 2011.

Although the sequence derives a degree of tonal unity from the edgy music, in no way does it seek to achieve coherence at the level of representation. Instead, we are confronted with the gaps in meaning created by the juxtaposition of apparently unconnected people and places and of dissimilar and seemingly unrelated elements. Because of these gaps in meaning, we know that the meaning may be in the gaps. There is a relationship there but one we cannot perceive, perhaps precisely because, in its very relationality, it does not reside in any one location, person, or thing. If we do hypothesize a link, however, it almost will certainly give a prominent place to the computer screens with their share prices, graphs of market fluctuations and currency indices. These visualizations of data seem to carry an implicit potential for connectivity and reach denied to the more mundane and human elements present which are all components of traditional forms of cinematic representation. The implied prominence of financial data is also favoured by a decentring not only of individual humans but also of any anthropocentric perspective. This partly relates to the absence of facial close-ups and shot-reverse-shot set ups and the resultant impossibility of tying what is seen to someone's point-of-view, an impossibility reinforced by repeated low angle and extreme high angle or aerial shots. But it also relates to the way in which we are presented with shots without humans (figure 1) or of anonymous groups or body parts engaged in co-ordinated, mechanical activities (the legs of commuters moving through doors (figure 2)) or functioning in a cog-like way, in combination with technological machines, as elements of some larger machinery (fingers on keyboards responding to market signals on computer screens). This machinic side of human activity is also brought to the fore by the rhythmic use of camera movement (the many tracking shots), the beat of the music and the repeated use of fast motion filming with its capacity to drive normally unnoticed patterns into view.

Insert figure 3 here: Figuring cinema's semiotic diversity, Ma part du gâteau, 2011. 
The disruption of anthropocentric perspectives and temporalities also allows cinema's semiotic diversity to become apparent. As the human face and especially the voice and language are marginalised (except in the sparse lyrics of the song), other elements assert themselves: pitch and rhythm; figures and graphs (figure 3); posters and graffiti; colours, shapes and forms; gestures and movements. Some, if not all, of these elements can routinely be found in film, of course, but they are typically subordinated to character, plot and language. ${ }^{3}$ Confirming this point, as the title sequence comes to an end and the plot begins to unfold, language reasserts its semiotic dominance and anthropocentric representation, with its facial close-ups, point-of-view shots, and psychologically motivated actions and reactions rediscovers its habitual primacy. It is as if, in the film's title sequence and first scene, the whole drama of cinema had been encapsulated: a medium whose own machinery and semiotic pluralism makes it ideally equipped to probe the onward march of machinic subjection seems forever condemned to return us to a world of centred human subjects. That this should happen in a film committed to recounting the interplay of financial capitalism and ordinary workers in the aftermath of the financial crisis is extraordinarily telling. It would seem that, if we are to find the machinic in cinema, we will need to look ex-centrically, around the medium's edges, at moments where cinema's own subject-centring machinery is paused, arrested or has yet to come into play. ${ }^{4}$

\section{Lazzarato, machinic subjection and semiotic pluralism}

The theoretical dimension of what precedes clearly needs to be expanded. It is here that the work of Lazzarato can help us. An Italian social theorist based in France, Lazzarato's key influences are Michel Foucault, Gilles Deleuze and Felix Guattari. Lazzarato's main project in relation to Foucault is to develop his work on the production of subjectivity under neoliberalism, especially but not only because, written in neo-liberalism's early period and before our current age of austerity and debt, Foucault's account might seem rather ambivalent if not positively sanguine (Lazzarato 2011, 2015). Lazzarato is indebted to Deleuze and Guattari for their account of the machinic and to Guattari for his unorthodox theory of semiotics, the latter being essential to an understanding of the complementary workings of both subjectivation and machinic enslavement.

It is worth re-emphasising, to begin with, that the concept of the machine, as deployed by Lazzarato, following Deleuze and Guattari, relates to something much more than the technical machine as a prosthetic tool deployed by a human subject. The machine is rather a functional whole or assemblage, incorporating material, semiotic and incorporeal as well as human elements $(2014,81)$. Rather than the factory, for example, being simply a container for machines, it is better seen as a machine itself, incorporating human elements into an assemblage involving not simply technical machines but also material flows and different forms of semiosis (diagrams, plans, balance sheets etc.). If, in Marx's time, the factory was the main site where machinic enslavement was concentrated, now, with the spread of mass and social media, mass consumption and information technology, the machinic is everywhere. While mechanisms of subjectivation produce discrete individuals by allocating social and economic roles, responsibilities, rewards and property rights, machinic subjection shatters the unity of the individual by incorporating sub- and supra-individual elements into machinic assemblages. As Lazzarato explains:

Not only is the individual of a piece with the machinic assemblage but he [sic] is also torn to pieces by it: the component parts of subjectivity (intelligence, affects, 
sensations, cognition, memory, physical force) are no longer unified in an 'I,' they no longer have an individuated subject as referent. Intelligence, affects, sensations, cognition, memory, and physical force are now components whose synthesis no longer lies in the person but in the assemblage or process $(2014,17)$.

Mechanisms of subjectivation are territorialising, in the Deleuzian sense: that is, they name, separate, specify and localize. Machinic enslavement, in contrast, is radically deterritorialising and dissolves specific identifications into broader processes. Both are necessary for the functioning of contemporary capitalism, one to allocate and justify roles, ownership and rewards, the other to insert human elements into complex assemblages from which profit can be extracted. If this seems too abstract, we might look at how it applies to something like mortgage debt in the American 'sub-prime' crisis. On the one hand, the mortgage system needed particular individuals to be financially and morally responsible for the repayment of specific sums to named banks with geographically located properties as collateral: on the other, debts were detached from individuals and locations, packaged up, traded, added to balance sheets, rated, speculated upon and reprocessed in complex derivatives. The functioning of the mortgage market required both of these very different but ultimately complementary machineries. In a similar way, a social media platform like Facebook constantly insists that we are unique, psychologically-rounded individuals, with our profiles, histories, friends, tastes and photographs. Yet at the same time, it works ceaselessly to plug fragments of our attention and affects into broader machineries that measure the popularity of pages and themes, select which content to show us, and monetize our data, gathering it up and selling it on to advertisers or, as we are now only too well aware, political campaigns.

It is because subjectivity is traversed and indeed constituted by both individualising and machinic processes in this way that Lazzarato is scathing about the work of leading contemporary theorists such as Alain Badiou, Jacques Rancière, Judith Butler or Slavoj Zizek who all, he suggests, focus on subjectivity and subjectivation to the exclusion of the machinic and thus render themselves incapable of generating an adequate account of contemporary subjection and how it can be opposed $(2014,13)$. In a similar way, he is critical of a similar range of thinkers for granting undue centrality to language in the realm of politics (Rancière) and production (Paolo Virno in his account of cognitive capitalism) and in the constitution of the subject (Butler and Zizek) (2014, 16-17). Machinic enslavement largely by-passes language and relies on a different form of semiotics.

Lazzarato turns to Guattari for his account of semiosis. The latter commences his four-part categorisation with a-semiotic signs that include things like crystal structures or DNA which, although they might seem to belong outside the normal domain of semiosis, contain information and shape forms, giving the lie to any sense of the inertness of matter or the objectified passivity of nature. Guattari's second category, symbolic semiotics, is initially associated with early human societies and relates to gesture, art, music, and dance, forms that, in their egalitarian co-existence and interaction, were an integral part of group life as opposed to something that sought to describe it from some exterior location. The third category, signifying semiotics, relates primarily to language, with its capacity to define and fix identities and meanings while separating a world of representation from the world of action. The fourth and final kind is what, following Guattari, Lazzarato calls asignifying semiotics and which encapsulates graphs, diagrams, digital data, computer code, balance sheets and so on (Lazzarato 2014, 39-49, 55-94). 
How do Lazzarato's discussion of forms of subjection and plural semiosis come together? As he himself puts it:

Social subjection mobilizes signifying semiotics, in particular language, aimed at consciousness and mobilizes representations with a view to constituting an individuated subject ...[M]achinic enslavement functions based on asignifying semiotics ... which do not involve consciousness and representations and do not have the subject as referent (Lazzarato 2014, 39)

Language plays vital roles of subordination, separation and reterritorialization that are essential for the functioning of capitalism. Firstly, the multiple, trans-individual, group or tribe-centred forms of symbolic semiotics must be 'hierarchized and subordinated to language,' (Lazzarato 2014, 69) in order to produce a defined reality (Lazzarato 2014, 72). Secondly, in the face of capital's capacity, as described famously by Marx, to melt all that is solid into air, language fixes the individuated identities, properties, roles and rewards without which unequal social relations could not be maintained (Lazzarato 2014, 94). Yet, precisely because of this capacity to stabilise representations, language lacks the mobility and flexibility that capital requires for its functioning. It is here that asignifying semiotics comes into its own: unencumbered by attachment to sedimented meanings, it is able to perform the vital roles of capture, evaluation and transfer that are so essential to capitalism as it harnesses and extracts value from a range of divergent activities $(2014,41)$. Moreover, while language and representation necessarily separate themselves from the 'reality' they describe, asignifying semiotics intervenes directly in material flows. As Lazzarato puts it, 'Instead of referring to other signs, asignifying signs act directly on the real, for example, in the way that the signs of computer language make a technical machine like the computer function, that monetary signs activate the economic machine, that the signs of a mathematical equation enter into the construction of a bridge or an apartment building, and so on' (Lazzarato 2014, 40-41). It is this reach and power that explain why, in the age of the ascendancy of financial capital and of the digital, asignifying semiotics has become the dominant form of semiotics.

At this stage, we might be tempted to throw up our hands in despair and suggest that, caught between the machineries of subjectivation and signifying semiotics, on the one hand, and machinic enslavement and asignifying semiotics, on the other, we are effectively trapped; pinned by one set of mechanisms; shattered and turned into cogs by the other. Yet, Lazzarato leaves room for hope. Firstly, he notes that neoliberal subjectivation is in crisis, that, in the age of debt and austerity, the previously preferred subjective figure of the entrepreneur-of-the-self can no longer maintain any pretence of general applicability (2014, $9-11 ; 2013,14)$. Secondly, he points to the tension between subjectivation and machinic enslavement; while one individualizes and territorializes, the other deterritorializes and potentially opens a space to imagine less oppressive reterritorializations. Thirdly, and relatedly, because Lazzarato frames machineries of both enslavement and subjectivation in terms of Deleuzian assemblages, with the contingent articulations that implies, and in contrast to more rigid systemic models, he leaves room for progressive reassemblages.

What is the place of cinema and its different machineries within all this? Predicatably, Lazzarato draws on Guattari again as he analyses the combination of symbolic, signifying and asignifying semiotics at work in cinema. He cites the following list: 
-The phonic fabric of expression that refers to spoken language (signifying semiology);

-The sonorous but non-phonic fabric that refers to instrumental music (asignfiying semiotics);

-The visual fabric that refers to painting (both symbolic and asignifying semiotics);

-The gestures and movements of the human body, etc. (symbolic semiologies);

-The durations, movements, breaks in space and time, gaps, sequence, etc., that make up asignifying intensities (Lazzarato 2014, 109)

He adds wistfully,

The cinema, whose effects derive above all from its use of asignifying symbolic semiotics ... represented for a brief moment the possibility of moving beyond signifying semiologies, of bypassing personalist individuations, and opening up possibilities that were not already inscribed in dominant subjectivations (Lazzarato 2014, 109 [my emphasis]).

While this remark echoes Lazzarato's more general discussion of the tension between signifying and asignifying semiotics, his specific judgement on cinema seems pessimistic: he suggests that its semiotic diversity is subordinated to the signifying 'machine,' so that the film industry functions as a form of group psychoanalysis, 'powerfully aiding in the construction of roles, and especially, in the fabrication of the individuated subject and his [sic] unconscious' (Lazzarato 2014, 108). Yet, he also notes that cinema's semiotic diversity opens it up to readings prioritizing different semiotic elements which, through their very diversity, reintroduce 'ambiguity, uncertainty, and instability into denotation and signification' (Lazzarato 2014, 110). This is what I sought to bring out with my own reading of the opening of Ma part du gâteau: the title sequence highlights the astonishing semiotic richness of cinema and its potential to bring our insertion into various interconnected machineries into the open. But it also underlines how, once the story proper gets under way, this richness is put in the service of the machinery of individuation, psychological motivation and a conventional cause-effect narrative chain. It is only by reading around the edges, ex-centrically, that we can bring cinema's subordinated elements into view.

This sense that cinema retains an unrealised or forever subordinated capacity for engagement with the machinic can be further developed if we look at how Lazzarato and Beller analyse the work of Soviet film-makers. For both thinkers, despite their differences, the development of cinema's powers has to be understood within the broader context of the capacity of industrial and consumer capitalism to organize perception. Both also focus on Dziga Vertov as the still unsurpassed example of a cinema that radically reorientates the medium's powers in progressive directions.

Lazzarato discusses Vertov in a text whose title, 'The cine-eye's war machine and the movement of the Kinoks mobilised against the Spectacle' (my translation), explicitly references Guy Debord. The latter famously defined the Spectacle as a social relationship mediated by images. Reversing the dynamic, Lazzarato suggests that the real task is to move beyond critique of the Spectacle and to develop cinema's capacity to constitute and organize the social body. He notes that the machineries that produces visibility, and therefore cinema, under capitalism are semiotic, technological, social and aesthetic. But he observes that, since Vertov, attempts to create a radical cinema have been aesthetic, 
political or social in isolation and have failed to generate the necessary reworking of the cinematic machinery in its combined facets. In contrast, Vertov's aesthetic and sociopolitical re-appropriation of cinema's powers brought together the capacity of the camera and montage to decentre an anthropocentric experience of time, duration and velocity, and a collective seeing and thinking that decentred the director-auteur. As the selfconsciousness of a human-technological hybrid, this revolutionary cinema emphasised the capacity of the machinic to free us from individualising subjectivations and not simply to enslave us (Lazzarato 2005).

Beller's not dissimilar starting point is the proto-cinematic nature of capitalism itself. He suggests that, by the time of the emergence of industrial capitalism, factories and markets had already begun to set image-commodities in motion (Beller 2006, 10). Also echoing Debord, he notes that, because of commodity fetishism, objects became images of themselves, made themselves 'photogenic' (desirable) and entered into circulation (Beller $2006,58,77)$. By connecting things and processes, Beller adds, money necessarily also performs its own montage, capturing different materials and activities, extracting them from specific contexts and editing them into its flows and processes (Beller 2006, 54). With a similar capacity to capture objects and processes of radically different type or scale within the general equivalence of its frame (a perception Beller takes from Deleuze) and operate its own montage, cinema is clearly a product of this broader context (Beller 2006, 105). But it also intensifies specific tendencies within it. Anticipating capitalism's more general evolution, it amplifies the affective dimension of commodity fetishism by capturing and putting to work the imagination and desire of spectators (Beller 2006, 21). Because it is organically connected to capitalism in this way, it has the potential to become the selfconsciousness of the workings of capitalist production (Beller 2006, 56). This is Vertov's wager. As Beller puts it, 'Vertov uses the cinematic machine to assemble the movement of matter in such a way that this movement becomes precisely the consciousness of material relations' $(2006,38)$. Like capital itself, Vertov's cinema gives an abstract value to each concrete moment captured in its frame. But where capitalist abstraction takes the form of exchange-value, Vertov's shots point towards a different abstraction, 'the totality of social production' (Beller 2006, 49). For them to achieve this, montage, with its ability to locate meaning in relationships, has to intervene. While Eisensteinian montage emphasizes the dialectical collision between shots, the Vertovian variant, 'is made of connections that dismantle the phenomenological (reificatory) effects of capital circulation and create a new relation to the social product at once collective and personal' $(2006,45)$. This brave project ultimately fails, however, because Vertov over-concentrates on cinema's capacity to generate consciousness and thereby fails to foresee capital's 'total penetration of the sensorium' (Beller 2006, 70).

This is where Eisenstein comes into the argument. In his desire to provide a 'libidinal supplement' that would engage the Soviet masses (Beller 2006, 118), he unwittingly anticipated the path consumer capitalism would take as it plugged itself deeper into the human psyche and put it to work. Pavlov, the celebrated physiologist, focused on controlling the reflexes of the biological organism. Frederick Taylor, the equally famous mechanical engineer, sought to perfect the scientific management of the production process. Effecting a synthesis of the two, Eisenstein developed a cinematic machinery that could mediate between the individual psyche and the needs of a new society (Beller 2006, 117-128). Preferring the affective hammer blows of his film-fist to Vertov's cerebral film-eye, he endeavoured to submit the psyche to a new wave of industrialisation (Beller 2006, 131). 
Ironically, it would be this vision that would triumph, but in the service of the capitalist revolution rather than the communist one.

Again, one is tempted to throw up one's hands in despair. If all cinema since Vertov has either failed to maintain a radicalism that, in any case, was profoundly rooted in the very specific circumstances of pre-Stalinian revolutionary Russia, or has become enrolled, more or less uniformly, in capitalism's drive to harness the human psyche, it becomes very difficult to differentiate between films or to retain any faith in cinema's powers. Here, it is worth contrasting Beller and Lazzarato. While both emphasize Vertov's re-assemblage of the cinematic machine to generate collective self-consciousness, their readings are different. By opposing Vertov to Eisenstein in such a polarised way, Beller leaves little space for a cinema that speaks to both affect and rational cognition. In contrast, Lazzarato is less focused on rational consciousness per se and more on film's capacity to connect to affect, perception and cognition. He leaves room for cinema to decentre the human and the individual without automatically plugging us into the machineries of consumer capitalism. He also accentuates, as we saw, the semiotic excess of cinema which gives even conventional films the potential to overflow the anthropocentric narratives that seek to domesticate them. Building on these insights, I will now return to the contemporary period as I seek to develop a more nuanced account of cinema's engagement with the machinic.

\section{Contemporary European film and machinic enslavement}

The pre-title sequence of Geyrhalter's Abendland begins with a nocturnal medium shot of a camera-like object on a hydraulic mounting emerging from a flat, dark surface (figure 4). The middle ground is occupied by a field with an unidentifiable crop. There are some lights in the background of the shot. As we watch, the object rotates, tilts and stops, before rotating a little more. We hear the whir of what sounds like an electric motor. We cut to an enclosed space in which a man in medium shot is watching what looks like an infra-red image on a monitor as, using a joy-stick on a desk, he controls the camera producing the image. Speaking to someone off-screen, he notes that there is nothing living to be seen, before identifying first a rabbit, then a patrol car. We cut to a more distant shot of the camera we saw at the start as it slowly retracts into what we now see is a van. Two men emerge from the rear compartment of the vehicle and drive off. The filming camera holds the shot for several seconds after the van has left. We cut to a very different location: we are in a shanty-style camp where one man is explaining to a group clustered around him that they will be transferred to other camps but that family groups will be kept near to each other. After several shots of the man and the group in animated discussion, we cut to a long shot of the same space, with all the shanties razed to the ground. Roughly in the centre of the shot, there is a small jet of water that presumably once supplied a tap. We cut to another darkened space, this time in what we deduce to be a neo-natal intensive care unit. By a cot, in long shot, a nurse cradles a child. Another shot shows a nurse in medium close up attaching a fragile infant to tubes and monitors. The noise of machinery mingles with the faint noise of a child crying. We cut to a medium shot of another infant with multiple sensors attached to them. The noise of a nurse's movements mixes with the whir of machinery. We cut to a long shot of a nurse by some computer screens near a cot. The nurse leaves the room but the shot is held for a good number of seconds. Our eyes are drawn to the bright glow of the screens. We cut to what looks like an empty parliament chamber. 
Insert figure 4 here: The border's machinic eye, Abendland, 2011.

What are we to make of this? Clearly, we are not dealing with the kind of documentary that seeks to develop characters or track their lives or opinions. Yet, clearly too, the montage invites us to make connections between shots and look for patterns. The first and third sequence have obvious resemblances. They foreground technologies and how they form complex assemblages with human actors. What we witness in the first sequence is an enhanced, human-machine seeing that is itself presented as part of a larger assemblage, which we presume to be a border, an apparatus in which the other car, the one seen on the monitor, also plays a part. What we witness in the third sequence is what one might call cyborg life involving new born babies plugged into breathing apparatuses, incubation units and an array of monitors which convert their vital signs into data which is in turn reconverted into graphs and coloured lights which 'speak' to the nurse. But, like the first sequence, by framing people alongside machines or showing functional spaces without visible people, the sequence also invites us to situate the humans and machines as part of a larger assemblage, in this case the neo-natal unit. The second sequence seems different. With its medium shots of individuals and groups interacting and its re-centring of human faces and voices, it potentially moves us towards a traditionally anthropocentric cinema. But the fact that the film never returns to the location or the characters takes it in a different direction. The sequence's over-arching meaning emerges from its positioning in a broader assemblage of shots and its relationship to the film's title. The latter, Abendland, is an oldfashioned term for the West, but, meaning 'land of the evening,' also points to the film's deliberate focus on the night-time, when artificial lights are most visible, and the hum of machines continues even as other activities cease. If, in Man with a Movie Camera, each shot, whatever concrete activity it foregrounds, points, as Beller observes, towards an abstract sense of the 'totality of social production,' here the abstraction that all shots and sequences point to is Europe or the 'Occident' and the assemblage of socio-technical machineries that produce it. Rather than focussing on any particular group of migrants, the camp sequence therefore invites us to place the sorting and displacement of migrants between the production of borders, on the one hand, and the elaborate machinery of care attached to (only) some fragile lives on the other.

Insert figure 5 here: The newsroom's enunciatory machinery, Abendland, 2011.

Other sequences focus on the European parliament, a beer festival, a care home, a papal speech in St Peter's Square, a CCTV centre in London, a news room, a demonstration against a nuclear waste train, an on-line pornography studio, a highly mechanised crematorium and a staggeringly large discotheque. Despite their diversity, all the sequences revolve around specific machinic assemblages in circumscribed though unnamed spatial locations. Not all accord prominence to technical machines in their imbrication with elements of human labour or attention, although some such as the newsroom sequence do. The latter begins by showing someone we assume to be a producer in a control room, with a colleague beside him and multiple screens in front of him. We move to a long shot of the back of a newsreader's head (figure 5). Beyond him we see a monitor with a reporter on location. Facing us but behind him is an autocue with the text to be read. In the background, as is typical in many modern news reports, we see people at their desks. The choice of 
shots, their framing and their editing within the sequence all come together to decentre and fragment the individual face and voice normally foregrounded by the news machine. Individual humans are shown as components of an enunciatory machinery. There might therefore seem to be a clear contrast between this sequence and those involving the discotheque or the beer festival. But what is striking about the discotheque sequence is the way in which its refusal to prioritize any particular face allows the mass choreography of human bodies, affects and gestures by musical rhythm to come to the fore. Although it lingers on certain individuals, the beer festival sequence also conveys a sense of mass coordination. It contains, for example, a shot of three men filling beer glasses, one providing empty ones, another filling two at a time, a third moving the full ones away. The differentiation of tasks might suggest individualisation but the men's rhythmic, co-ordinated and programmed gestures and the mise-en-scène of multiplicity (the many glasses) point towards a becoming-mechanical of the human body (figure 6). More broadly, tying each activity into the broader functionality of the whole, the sequence's editing emphasises how the festival itself is a complex assemblage of machinic elements of which synchronised affect and movement are mere parts.

Insert figure 6 here: Becoming machine-like, Abendland, 2011.

In its capacity to generate an overarching sense of the production of Europe by assembling sequences of geographically dispersed machinic processes, Geyrhalter's film rivals the scope and ambitions of Vertov's masterwork. Like its predecessor, it is able to bring the machinic to the fore by decentring narrative and the individual psyche. Although it is much less obviously a montage-film, editing, cinema's own core asignifying semiotic, is nonetheless essential to its move away from the concrete and specific to the more general and abstract. In contrast to Vertov's work though, it does not belong to a cinema that aspires to be the immanent self-consciousness of a machinic revolution. Rather, it evidences a faith in some of the traditional tools of non-mainstream film to bring usually unnoticed socio-technical machineries into visibility while remaining carefully separate from them. Editing, the long take, the long shot, and judicious framings and camera placements all come together to decentre individual faces and voices and bring machines, the plural semiotics linked to their functioning, and the imbrication of human cogs within them, into view and audibility. This is a cinema that invites contemplation and distance, its own quiet machinery clearly distinct from the machineries of exclusion, care, politics, surveillance or news production that it invites us to observe. It is perhaps telling that in the final shot of the film, a long tracking shot in the discotheque, the assembled revellers part in front of the camera as if it were an alien object, a cog from the wrong kind of machine, disrupting their absorption.

Lucy, Besson's English-language, CGI-laden, Scarlett Johansson vehicle is different in almost every imaginable way from Abendland, its own spectacular and affective machinery seeking to plug into our psyches and put them to work rather than generate quiet detachment. Predictably, it has a cartoon-like plot. Its eponymous heroine (Johansson) is manoeuvred by her wastrel boyfriend, Richard (Pilou Asbæk), into delivering an attaché case to Mr Jang (Min-sik Choi), a mob boss. The bag contains four bags of a synthetic version of a hormone, $\mathrm{CPH} 4$, supposedly released in the mother's womb to trigger a baby's development. Lucy, along with three other characters, is made to become a drugs mule by having her abdomen cut open and a bag inserted. When she resists a sexual assault by one 
of her gaolers, she is kicked in the stomach, the bag bursts and a transformation begins. The chemical unlocks her unused brain capacity. She develops super-intelligence and supersensitivity. She learns Mandarin almost instantly from a laptop and quickly becomes a medical expert but can also perceive natural flows (the rising sap in trees) and her own bodily processes. She can read the gangster's memories by pressing her thumbs into his head. She flies to Paris (it being a French film, despite appearances) to meet up with Professor Norman (Morgan Freeman), an authority on brain potential, and enlists the help of a French policeman, Pierre del Rio (Amr Waked) to round up the other mules and seize the remaining product. Meanwhile, her powers continue to develop: she can shift shape but also risks losing form altogether, as notably occurs as she is flying to Paris and starts to dissolve into a stream of molecules before regaining control. She can also interact at frightening speeds with laptops, perform telekinesis and see, sift and listen to a myriad of mobile phone conversations. She finds Norman and his team of scientists, absorbs the remaining hormone and breaks out of her body, connecting to whatever electronic devices (camera, copier or computer) there are in the laboratory. She also begins to travel in time and meets Lucy, the humanoid mother of humanity, touching finger tips, echoing Michelangelo's fresco 'the Creation of Adam', in a way that suggests she may have retrospectively triggered a matrilineal human evolution. Mr Jang, still on her trail, breaks through the police cordon, and fires his gun at the back of her head only to see her body dissolve and be shot himself by del Rio. The dark reddish-black substance Lucy has become, and which has merged with all the electronic devices, forms a hand and passes a pen-drivelike object to the Professor who concludes that it must represent the next generation of computer. When the policeman wonders where she is, she takes over the screen of his mobile phone to message, 'I am everywhere.'

In some ways, Lucy might respond well to the kind of ideological analysis that Fredric Jameson performed on Jaws (Spielberg, 1975). Jameson famously read that film in terms of how it invited the spectator to participate vicariously in the triumphant alliance of state authority (Roy Scheider's sheriff) and science and technology (Richard Dreyfuss's oceanographer) even as an older America of small business, the war and the New Deal (Robert Shaw's small fisherman) was cast aside (Jameson 1979, 142-144). In Lucy's case, we are invited to bask in the reflected glow of the utopian alliance between the eponymous everywoman / superheroine, Professor Norman's scientific knowledge and Inspector del Rio's state authority, with the discarded figure being Mr Jang. The latter is ostensibly just a gangster, but, a deeper level, and in a familiar way, embodies the unacceptable face of a capitalism for which people are either disposable tools or customers and for which human potential (the maternal growth hormone) is simply a resource. This facile and rather clichéd resolution of contradictions through the narrative elimination of their undesirable consequences is relatively uninteresting. Where the film is more noteworthy is in how it seeks to reconcile another related set of tensions, this time between the individual and the machinic, the human and the technological, a contradiction perhaps best expressed in the closing scene when Lucy disappears into technology but is still fully present to herself and others, although now ubiquitous in a god-like manner.

The film's central conceit, a long-since discredited claim recycled by Professor Norman, is that humans only use $10 \%$ of their cerebral capacity, the release of the unlocked $90 \%$ being triggered in Lucy's case by ingestion of the synthetic hormone. What I would suggest is that this reference to un-accessed brain-power is a displaced way of talking about the gap between collective humano-technological potential (our alienated machinic powers) 
and the paltry capacities of individual humans. Rather than asking us how we might collectively take control of this resource, the film instead offers us the fantasy of the reempowered individual. The initial Lucy, with a branded coffee in her consumer hand, is our mirror image as, an unaware cog, she blunders into the (criminal) machinery in which her body, a mere container, is to be put to work. In contrast, the new, empowered Lucy masters everything surrounding her, even those things and processes to which humans do not habitually have access. Apart from her improbable powers of tele-kinesis, she can control radio and television signals and access and sort mobile phone signals. Her initial interaction with laptops simply allows her to plunder and internalize the resources of the internet but she later herself merges with a range of devices including mainframes and takes on the ubiquity of the network itself. She can not only read human languages: she has access to the signals in her own brain and those of others. More broadly, she can feel the rotation of the earth, biological flows and the circulation of her own blood. The movements of life and matter become accessible to her as information even as she gains access to all the different forms of semiosis that surround her, including, crucially, the asignifying ones that normally by-pass human senses. At the same time, and in an implicitly interconnected way, she develops the capacity to reshape her own form, be it her hair colour, her limbs or, ultimately, her brain.

At this stage, we seem to have come full circle and returned to an enhanced version of the ideological reading I initially suggested but with the role of the everywoman figure (Lucy) fleshed out in a way that brings the contradictions of contemporary subjectivity to the fore. Lucy is contemporary of the age of information, bio-engineering, and networked global connectivity but, as the film progresses, she moves from simply being a resource, terminal or flexible and semiotically limited cog who takes form from whatever assemblage she is inserted into (including drug trafficking) to being the semiotically omni-literate agent of her own flexibility and connectivity. What plays out over her body therefore is the fundamental tension between the two forms of subjection: subjectivation and machinic enslavement, one which centres and territorializes us, the other which tears us apart. The tension takes on dramatic visual form in the aeroplane sequence when, thanks to the CGI, Lucy starts to dissolve into a stream of matter and energy only to pull herself back together, ready for her later apotheosis when she becomes one with networked machinery while remaining fully herself. Between these two emblematic moments, what is played out is the threat of the dissolution that the contemporary subject faces at the hands of machinic enslavement and its narrative containment. The role of CGI within the drama is crucial. Although its ostentatious presence, and the digital processes that we know lie behind it, could draw our attention away from the merely human to cinema's repressed machinic and asignifying substrate, it is in fact used to bring the threat of human disintegration within the realm of representation and narrative all the better to contain it. This is the condition of our continued enjoyment: having allowed our individual and collective affectivity to be plugged into the cinematic machine, we are rewarded by the reassurance that the heroine has not simply been absorbed. We share the policeman's concern that she may have disappeared but, like him, we are persuaded by Morgan Freeman's avuncular confirmation that she is somehow still there as guarantor of an anthropocentric future. ${ }^{5}$

George's Vers Madrid, a poetic, black and white documentary about the Spanish 'occupy the square' movement of 2011, moves us diametrically away from Lucy's kind of mainstream cinema but, in its proximity to its protagonists, also refuses the detached observation of Abendland. The film mainly consists of sequences showing aspects or phases 
of the occupation in the Plaza del Sol. There are sequences of classic occupy-style meetings, with their turn-taking, hand gestures and search for consensus. We also see smaller, more intimate, working group discussions. There are more ludic interludes; a sequence of music and dancers; another sequence with someone in costume imitating the then right-wing mayoress of Madrid leading a symbolic poor person on a lead while haranguing the crowd; two brief sequences with collective drumming on a corrugated barrier (figure 7); a montage of hand-made posters and artworks that gives way to more discussions. There are sequences of construction (building temporary structures) and maintenance (a cheerful clear-up after a downpour). There are sequences when the broadly static occupation gives way to a march, with defiant chants, drums and singing. But there are also repeated shots of what we take to be a police helicopter and of uniformed police officers watching or moving in. The collision foreshadowed by such shots develops into sequences of active confrontation with rapid movement of both protestors and officers. All these shots and sequences come together to suggest, not so much an exact chronology of the movement, but a series of moods and intensities loosely structured by a broad progression from the ludic and consensual to the confrontational. Interspersed in their succession, we see a less tightly related series of shots and sequences that look to a broader context: unfinished housing developments and posters relating to them; statues, some religious, some not, and the Francoist civil war monument, the Valle de los Caidos; empty streets and rough sleepers; natural elements such as flowers, leaves or running water. Also interspersed with all the above are shots of a solitary African migrant, the most individualised protagonist, recounting his precarious life in Spain and his dangerous journey to the country. The latter seems to motivate shots of the coast and the sea. A potential bridge between the migrant and the occupation is provided by one of the small discussion groups which debates the need for the revolution to be mestiza, culturally hybrid, if it is to exist at all. A more indirect connection could be hypothesized between the migrant, the rough sleepers and the occupiers in relation to their precarious, unstable or improvised presence in urban spaces. But there is also an implicit invitation to see the occupation as an interruption and exception, something that cuts across the background of the financial crisis, the housing crash associated with it and other less progressive Spanish traditions and contains the potential to reorganize the elements surrounding it. It is here that the shots of nature perhaps fit in. Something new may be growing in the Spanish spring. The film, like Abendland, draws attention to the power of montage and its capacity to suggest relationships that exceed any particular image or setting, but here the suggested connections are more fluid, undoubtedly due to the film's poetic nature and its refusal to develop the commanding or totalizing overview that would undermine its proximity and openness to what it is exploring.

Insert figure 7 here: The collective body and its wall of sound, Vers Madrid, 2012.

Insert figure 8 here: the enunciatory machinery of the occupation, Vers Madrid, 2012.

The film mobilises montage, other machinic elements and semiotic pluralism as it approaches the socio-political machinery of the occupation. Although some shots and sequences might seem to prioritize individual faces and voices, the framing, shot composition and editing together emphasize how individual elements are in fact subsumed as consenting cogs in the larger enunciatory machinery that surrounds them. Our attention 
is drawn to the temporary platform, the microphone, the person organising turn-taking, and the signer (figure 8). More importantly, we see multiple shots of the crowd. Some of these are medium shots of individual faces, or small groups, sitting on the ground, facing the speaker. Others are more general shots as the crowd responds through sounds or, more typically, gestures of assent or occasional disagreement (figure 9). While a conventional shot-reverse-shot organisation, returning repeatedly to a single listener, might suggest individual attention, here shots of speakers are typically followed by successive shots of different listeners, the editing thus emphasising the coming into being of a shared attention, itself a precondition for the formation of a collective voice which emerges, not from a single individual, but from the machinery of vocal and gestural enunciation and receptivity assembled by the occupation. It would be misleading, however, to overemphasize the voice to the exclusion of other elements of the collective body revealed by the film through its editing and its semiotic pluralism. Through the sequences of dancing, singing, drumming, marching, running and struggle, and the shots emphasizing gestures, facial expression and the spatial disposition of groups, the film brings a mobile collective body into visibility and audibility. This is not the fusional mass, class or national body that an earlier political cinema might have produced. It is an assembled body composed of reflective and consenting cogs in a way emphasized by the many close-ups or medium close-ups of pensive faces and the foregrounding of the machinery for the production of consensus. It is also an unstable and vulnerable body as shots of its improvised, impermanent spatial architecture and sequences of police repression underscore. If, an integral part of an ongoing revolutionary process, Vertov's work could aspire to be the immanent selfconsciousness of a collective, here the relationship is less immediate. George's film comes after the end of an occupation whose political legacy, whilst still developing, is uncertain. Yet, it nonetheless offers itself as a deferred self-consciousness to those of us pondering the shape a contemporary political movement should take, its own machinery and semiotic pluralism inviting us to develop not a platonic, or purely linguistic idea of what forms new collective bodies might take, but, as the risk of tautology, a felt sense of a corporeal, affective as well as cognitive assemblage.

Insert figure 9 here: The eloquence of the collective body, Vers Madrid, 2012.

\section{Conclusion}

Inspired by Lazzarato and Beller, my earlier discussion might have seemed to suggest that, cinema was forever torn between the Vertovian and Eisensteinian poles as either the immanent self-consciousness of an emergent humano-machinic collective body, or a machinery for plugging into the human psyche and affectivity and putting them to work. What I have sought to develop through my analysis of Ma part du gâteau, Abendland, Lucy and Vers Madrid is a more nuanced sense of how cinema's machinic powers and plural semiotic resources may be mobilised. Ma part du gâteau showed that, even in classically anthropocentric narratives, there is an undomesticated machinic and semiotic excess that, when subjected to ex-centric readings, may force other machineries into view. More systematically ex-centric with respect to mainstream cinema, Geyrhalter's Abendland underscored how cinema's own machineries (editing, the long take, the long shot, camera positioning) can be judiciously used to refuse anthropocentric perspectives and make our cog-like insertion into multiple machineries available for contemplation. Lucy provided a telling example of a cinema which uses all the machinic tools at its disposal to recentre the 
subject and to provide placatory representations, while implicitly acknowledging the radical disempowerment of contemporary human cogs. Finally, systematically ex-centric but also politically committed, Vers Madrid shows how cinema can connect its own machinery and semiotic pluralism to the machinery and semiotic diversity of an oppositional movement to help us see, feel and hear (and not simply represent) the form an oppositional body might take as it seeks to renew democratic forms. As it brings this collective subject into view, the film reminds us how, by becoming self-aware components of a progressive movement, we can move beyond the ultimately sterile opposition between individual subjects on the one hand and machinic cogs on the other, an opposition in the face of which, unable to imitate Lucy's magical resolution of contradictions, we are always tempted to retreat to the familiar reassurance of established identities.

\section{References}

Beller, Jonathan. 2006. The Cinematic Mode of Production: Attention Economy and the Society of the Spectacle. Lebanon, NH: Dartmouth College Press.

Brown, Wendy. 2001. Politics out of History. Princeton and Oxford: Princeton University Press.

Brown, Wendy. 2015. Undoing the Demos: Neoliberalism's Stealth Revolution. New York: Zone Books.

Chion, Michel (1999), The Voice in Cinema (trans C. Gorbman). New York, Chichester: Columbia University Press.

Harbord, Janet. 2016. Ex-centric Cinema: Giorgio Agamben and Film Archeology. New York and London: Bloomsbury.

Jameson, Fredric. 1979. 'Reification and Utopia in Mass Culture.' Social Text, 1, 130-148.

Lazzarato, Maurizio. 2005. 'La machine de guerre du Ciné-Oeil et le movement des Kinoks lancés contre le spectacle,' http://www.korotonomedya.net/kor/index.php?id=9,78,0,0,1,0 (consulted 17/05/2018).

Lazzarato, Maurizio. 2011. La Fabrique de l'homme endetté: essai sur la condition néolibérale. Paris: Editions Amsterdam.

Lazzarato, Maurizio. 2014. Signs and Machines: Capitalism and the Production of Subjectivity. Los Angeles: Semiotext(e) (translated by J. D. Jordan).

Lazzarato, Maurizio. 2015 (2013). Governing by Debt. South Pasadena: Semiotext(e) (translated by J. D. Jordan). 


\footnotetext{
${ }^{1}$ There is no attempt in this piece to develop an argument that might be somehow specific to European cinema. My hope is that will it have a broader valency. It could be argued nonetheless that my choice of films highlights some of the range and diversity of European film-making: Lucy, although French, has a distinctly Hollywood feel; Ma part du gâteau is a classic example of the middle-budget film-making that the French state support system helps survive; the avant-gardist and politically committed Vers Madrid also owes its existence, at least in part, to the French support system and its ability to find an audience to both a French state supported arthouse circuit and the international festival circuit; the only film of the four that takes Europe as its specific focus, a highly-creative documentary, Abendland is also the kind of European film that relies on the international arthouse and festival circuit.

${ }^{2}$ On moralism as anti-politics, see Brown (2001, 18-44).

${ }^{3}$ Michel Chion suggests that the soundscape of mainstream cinema works to centre the voice in the same way as its image centres the face (Chion 1999, 5-6).

${ }^{4}$ I take the notion of ex-centric cinema from Janet Harbord's fine book (2016).

${ }^{5}$ Although the gendering of individualised subjects is not the focus of this piece, it is worth underscoring how, when they centre subjects, the films discussed work to cement existing gender identities. This is clear in Lucy. Despite what might be seen as her refreshing super-hero status, the main character moves from being an unaware consumer, a role often devolved to women, to becoming the maternal origin of new forms of life. The men play stereotypically masculine roles as scientist, policeman and (drug-lord) entrepreneur. Likewise, in Ma part du gâteau, as precarious worker and domestic cleaner, the lead character takes on roles often or stereotypically associated with women, even as the macho, risk-taking, unempathetic broker she tangles with clearly aligns with male stereotypes.
} 